Funding needed for private enterprise in genome sequencing

\section{Boston}

A LITTLE over a year ago, Harvard biologist Walter Gilbert surprised many colleagues and observers by resigning from a National Academy of Sciences advisory committee on the human genome project and announcing his intention to start a private company that would push ahead rapidly with both mapping and sequencing the human genome.

At that time, Gilbert's plans added fuel to a controversy over the appropriate goals and timing of the human genome project. Now, just as there appears to be a

$$
\text { ... and for just } \$ 10,000 \text {, }
$$
you can have a gene named

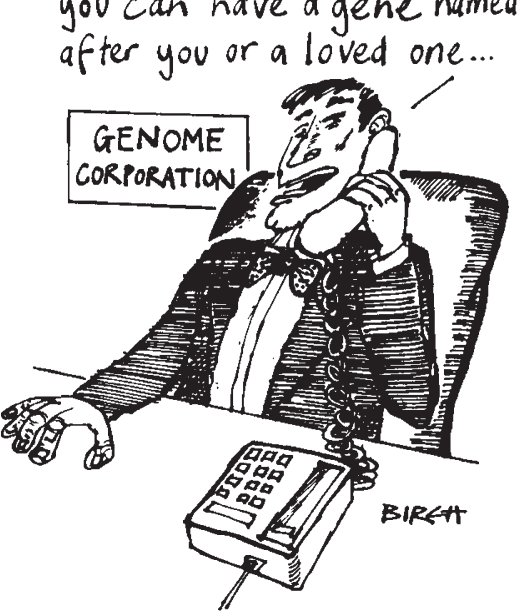

growing consensus on the merits of launching the project in the near term, there also seems to be far less disagreement over the role of the private sector.

"While everyone else is fussing, I might as well go do it ...", Gilbert, a Nobel laureate and former chairman of Biogen, told the press in February 1987. In the absence of any serious movement on the national level, his Genome Corporation, Gilbert said, would aim to complete a physical map of the human genome within a year of the company's start-up and to sequence major regions of the genome within three years thereafter.

One year later, Gilbert still seeks the funds to launch his private venture, although he remains hopeful that the company will materialize, perhaps as early as this summer. Gilbert says some of his financial problems result from the October 1987 crash of the stock market.

But as several scientists in the field noted, Gilbert's plans today are markedly different from his original outline. Eric Lander of the Whitehead Biomedical Institute at MIT sees Gilbert's plans as having been scaled down. Lander says he is in favour of "whoever can do the sequencing most efficiently at the lowest cost", providing that it is made publicly available. But he notes that in the course of the debate over the topic, many have under-estimated the size of the project. "With all the ballyhooing, it is important to remember that nobody has even sequenced $E$. coli yet," he says.

As a national genome project has slowly begun to move forward under the auspices of the National Institutes of Health (see Nature 332, 99; 1988), Gilbert acknowledges that his view of the role of his company - and of the private sector more generally - in the genome project has changed.

Gilbert now sees his venture as primarily a sequencing company that will try to interrelate with government efforts along the same lines. Charles Cantor of Columbia University, who sits on Genome Corporation's board, agrees there will be a need for contract work to complete the sequencing of the 3,000 million base pairs of the human genome.

Cantor suggests that once the goals of the genome project are clearly defined, companies might vie for contracts by performing sequencing work on a pilot scale and being judged according to their speed, cost and quality control. He expects that private companies will also have a role in the development of instrumentation.

Seth Shulman

\title{
Genentech's boom is boosted by new clinical trial data
}

\section{Berkeley}

THE biotechnology company Genentech is riding high, thanks to new successes for its clot-dissolving drug, Activase (tissue plasminogen activator, TPA). On 26 March, favourable results were announced from two clinical trials of TPA; a placebo-controlled mortality study with heart-attack patients, and a trial comparing TPA to urokinase as a treatment for pulmonary embolism.

The heart attack study, involving more than 700 patients and conducted by the European Cooperative Study Group, showed a 51 per cent reduction of mortality at two weeks when patients were treated with TPA versus a placebo. The results lived up to Wall Street rumours that TPA would better streptokinase and Beecham Group's Eminase, a chemically modified form of streptokinase, both of which have shown mortality reductions of just under 50 per cent. Franz Van de Werf, director of the study, called the TPA results "the best in-hospital survival ever reported in a large-scale study of thrombolytic agents". This may help to justify the cost of Activase, at $\$ 2,200$ a dose, ten times the cost of streptokinase.

In the second study, conducted by Harvard Medical School, 45 pulmonary embolism patients were treated with either TPA or urokinase, the current treatment of choice for pulmonary embolism. The investigators found TPA to be superior for rapid clot dissolution and reduction of pulmonary artery pressure.

Genentech is expected to apply for FDA approval of TPA as a treatment for pulmonary embolism later this year.

In the first few months since its approval for treatment of heart attack patients, Activase has established a wide following in the United States. Stuart Weisbrod, an analyst with Prudential Bache Securities in New York, says this is due in part to aggressive marketing, but also to data showing that the effectiveness of streptokinase drops sharply if the drug is not administered within an hour of the heart attack. Weisbrod recently asked 1,000 cardiologists their opinion of TPA. Of the 150 responses he has received so far, he said the doctors overwhelmingly chose TPA as safer, as it is often difficult to know exactly when a patient's heart attack occurred.

Analysts say Activase's US success is unlikely to be mirrored in Europe. Streptokinase has a strong medical following in Germany, and Eminase, already on the market in Europe, has better clot-specificity than streptokinase, and other advantages over TPA as well, such as a longer lifetime in the bloodstream and a lower price, at about $\$ 1,000$ per dose. In a study published in the 12 March issue of The Lancet, Eminase gave a 47 per cent reduction in 30-day mortality in heart attack patients. The drug is unlikely to reach the US market before 1990 .

Sales of Activase have slowed from the $\$ 58$ million reported for the last 6 weeks of 1987 (see Nature 331 , 202; 1988), but stock analysts say that was predictable, as hospitals complete the stocking of their shelves. Denise Gilbert, of Montgomery Securities in San Francisco, estimates January's sales at $\$ 20$ million, and February and March at $\$ 11$ million each. Most analysts predict 1988 sales to be between $\$ 250$ and $\$ 350$ million. Company officials will not predict 1988 sales, but point out that 2,000 patients a week are now being treated with TPA, twice the January treatment rate.

While basking in the success of Activase, Genentech has boosted its stock to a listing on the New York Stock Exchange. Marcia Barinaga 